\title{
PREÁMBULOS DE LAS CONSTITUCIONES DEL BRASIL
}

DALMO A. DALLARI 
SUMARIO

I. Preámbulos Reveladores.- II. Los Preámbulos de las Constituciones HISTÓRICAS.- 1. Constitución de 1824.- Preámbulo.- 2. La Constitución de 1891.- Preámbulo.- 3. La Constitución de 1934.- Preámbulo.- 4. La Constitución de 1937.- Preámbulo.- 5. La Constitución de 1946.Preámbulo.- 6. La Constitución de 1967.- Preámbulo.- 7. La Constitución de 1969.- Preámbulo.- III. LA CONSTITUCIÓN BRASILEÑa dE 1988.- Preámbulo.- 


\section{PREÁMBULOS DE LAS CONSTITUCIONES DEL BRASIL}

POR

DALMO A. DALLARI*

\section{PREÁMBULOS REVELADORES.}

La simple lectura de los Preámbulos de las Constituciones que ha tenido Brasil es suficiente para revelar, en sus líneas fundamentales, la historia constitucional brasileña. Esa revelación resulta clara por el hecho de que en el inicio de cada Preámbulo se encuentra la identificación de la institución y del órgano o personas que hicieron la Constitución, por donde ya se tiene una idea de las circunstancias políticas en que cada una de las Constituciones brasileñas fue realizada.

Por el examen de los Preámbulos se verifica que, de las ocho Constituciones que ha tenido Brasil, apenas cuatro fueron elaboradas por una Asamblea Constituyente. Es también expresivo y revelador, demostrando cierta coherencia y contribuyendo a la percepción de las circunstancias políticas, la peculiaridad de que sólo los Preámbulos de aquellas Constituciones, hechas con arreglo a criterios democráticos, hacen referencia a la democracia y a la libertad como objetivos a ser conseguidos por la Constitución.

Quien tuviera como referencia sólo el texto de los Preámbulos podría llegar a conclusiones equivocadas. En efecto, aquel hecho -la

* Profesor de la Facultad de Derecho de la Universidad de São Paulo y Vicepresidente de la Comisión Internacional de Juristas. Traducción de Luis Felipe López Álvarez, Profesor de Derecho Administrativo del Centro Universitario Villanueva (Madrid). 
referencia expresa a la democracia y a la libertad-podría ser tomado como indicador de la autoridad y relevancia que los líderes políticos predominantes del momento pretendían dar a cada una de las Constituciones o que éstas adquirieran enseguida. Entre tanto, el examen de la evolución de los acontecimientos no permite que se generalice esa ligazón considerándola válida para todos los casos. En realidad, como será aclarado con más detalle cuando se haga el análisis del contenido de los Preámbulos resaltando algunos puntos básicos de las circunstancias políticas en que surgió cada Constitución y de las que la siguieron, hubo Constituciones que fueron igualmente decretadas tanto por líderes democráticos como antidemocráticos y que, no obstante, influyeron de modo diferente en cuanto al reconocimiento $y$ respeto de los derechos fundamentales, o de algunos de ellos.

Así, también, el origen democrático o autoritario revelado por el Preámbulo no guarda relación con la duración de las Constituciones. Baste señalar que la Constitución de 1824, impuesta por un decreto imperial, duró sesenta y cinco años, en contraste con la de 1934, elaborada por una Asamblea Constituyente elegida por el pueblo, que duró apenas tres años. La de 1891, también realizada por una Asamblea elegida por el pueblo, fue mantenida durante treinta y nueve años, al paso que la de 1967, hecha de forma antidemocrática, tuvo una duración de apenas dos años.

Como última observación preliminar, es interesante señalar que en Brasil, solamente ahora, después de la elaboración de la Constitución de 1988, se comienza a dar importancia al Preámbulo de la Constitución, reconociendo su carácter de precepto jurídico $y$, por tanto, la exigencia jurídica de respetarlo y tenerlo en cuenta en la interpretación de los artículos de la Constitución y en el control de constitucionalidad de las leyes $y$ de los actos jurídicos. En realidad, los Preámbulos siempre fueron vistos como simples fórmulas retóricas, desligados del cuerpo de la Constitución y sin ninguna eficacia jurídica. En casos de decreto autoritario de una nueva Constitución el Preámbulo fue utilizado como una especie de manifiesto político, por medio del cual se procuró justificar la imposición de una nueva carta constitucional, tomando como pretexto el interés del pueblo.

La excepción a esa práctica sucedió con la Constitución de 1967, lo que se explica por el hecho de que, en realidad, fue una imposición autoritaria pero con la pretensión de simular una decisión democrática, contando con la participación, aunque muy restringida, de casi todo el Parlamento nacional. Por ese motivo, nadie quiso asumir la responsabilidad de explicar en el Preámbulo la razón por la cual la 
Constitución democrática vigente hasta aquel año, la de 1946, que podría ser perfeccionada a través de enmiendas constitucionales, estaba siendo sustituida por otra.

Una señal muy expresiva de la poca autoridad atribuida a los Preámbulos y de su irrelevancia en la práctica jurídica brasileña es el hecho de que las innumerables obras publicadas por constitucionalistas, comentando las Constituciones brasileñas, nunca incluyan comentarios o análisis de los Preámbulos. Lo mismo se verifica en las obras doctrinales de Derecho Constitucional brasileño que, sistemáticamente, ignoran los Preámbulos. Eso demuestra que, también para los constitucionalistas, el Preámbulo no era considerado parte de la Constitución o, por lo menos, una directriz para la interpretación y aplicación de los artículos de la Constitución.

Esa concepción comenzó a cambiar a partir de la vigencia de la Constitución de 1988, como expresión de un nuevo constitucionalismo que llegó también a Brasil, debiendo ser reconocida, para ese cambio, la gran influencia ejercida, sobre todo, por el constitucionalista portugués José Joaquim Gomes Canotilho. Otros eminentes juristas también contribuyeron a esa actualización del pensamiento constitucional brasileño, pero la obra de Canotilho fue, sin duda, la de mayor influencia, probablemente por la gran repercusión que tuvo en Brasil la nueva Constitución de Portugal, de 1976, como también por el hecho de haber sido publicada en portugués.

\section{LOS PREÁMBULOS DE LAS CONSTITUCIONES HISTÓRICAS.}

\section{Constitución de 1824.}

La primera Constitución brasileña es de 1824. Proclamada solemnemente la independencia de Brasil el 7 de septiembre de 1822, rompiendo los lazos coloniales con Portugal, asumió el gobierno brasileño el entonces Príncipe Regente Don Pedro, hijo del rey portugués Don João VI. Influenciado por los líderes políticos brasileños, y también por el hecho de que en Portugal había ocurrido una revolución liberal teniendo como resultado la conversión de la Monarquía Absoluta portuguesa en Monarquía Constitucional, Don Pedro definió a Brasil como Imperio, haciéndose coronar con el título de Don Pedro I, Emperador de Brasil, y convocando poco después una Asamblea Constituyente. 
Elegida la Constituyente en 1823, se verificó que adoptaba rumbos bien diferentes de los deseados por el Emperador, que había nacido y se había educado en una corte absolutista. No tolerando las discrepancias, sobre todo en lo que se refería a la limitación de sus poderes, y considerándose ofendido, el Emperador disolvió la Constituyente, pero preocupado por mantener el compromiso de dar una Constitución a Brasil, mandó que un grupo de eminentes políticos, de su entera confianza y afines a su pensamiento, elaborasen un proyecto.Para atenuar el carácter de imposición antiliberal, el Emperador pidió y obtuvo la aprobación para su proyecto de algunos Ayuntamientos $y$, después de eso, el 25 de marzo de 1824, publicó un decreto poniendo en vigor el proyecto elaborado a su instancia. En ese proyecto se contenían algunos preceptos liberales, inclusive una declaración de derechos y la separación de poderes, al mismo tiempo que eran asegurados amplios poderes para el Emperador que, en relación a determinadas materias, tenía poder absoluto. Así nació la primera Constitución brasileña, con el siguiente:

\section{Preámbulo}

Don Pedro l, Por Gracia de Dios, y Unánime Aclamación de los Pueblos, Emperador Constitucional y Defensor Perpetuo de Brasil: Hacemos saber a todos Nuestros Súbditos, que habiéndo-Nos requerido los Pueblos de este Imperio, juntos en Cámaras, que Nos cuanto antes jurásemos e hiciésemos jurar el Proyecto de Constitución, que habiamos ofrecido a sus observaciones para hacerlas después presentes a la Nueva Asamblea Constituyente; mostrando el gran deseo, que tenían, de que se observase ya como Constitución del Imperio, por merecerles la más completa aprobación, y esperar de ella su individual, y general felicidad Política: Nos Juramos el antedicho Proyecto para observarlo y hacerlo observar, como Constitución, que de ahora en adelante queda siendo de este Imperio; la cual es del tenor siguiente: EN NOMBRE DE LA SANTÍSIMA TRINIDAD.

Como se comprueba, Don Pedro I asume la autoría del proyecto, pero el Preámbulo contiene una ambigüedad cuando afirma que los pueblos del Imperio "juntos en Cámaras» pidieron que el Emperador jurase el proyecto que él había remitido para recibir observaciones y ser después éstas presentadas a la nueva Asamblea Constituyente. Dice también el Preámbulo que las Cámaras aprobaron íntegramente el proyecto y pidieron que fuese inmediatamente convertido en Constitución del Imperio para "general felicidad Política». Las Cámaras 
ahí referidas de modo muy vago fueron apenas algunos Ayuntamientos, que, sin otra perspectiva, decidieron manifestar su acuerdo con los términos del proyecto, sugiriendo que fuese publicado y puesto en vigor como Constitución.

En realidad, no habia otra posibilidad para la limitación del poder absoluto del Emperador y la conversión de Brasil en Monarquía Constitucional, lo que, en aquella circunstancia, era una aspiración política generalizada entre los líderes políticos brasileños. La referencia a una "Nueva Asamblea Constituyente», a la cual el Emperador tenía la presunta intención de someter el nuevo proyecto, era apenas un artificio para sugerir el espíritu democrático de Don Pedro pues, teniendo en cuenta el pésimo resultado de la primera Asamblea, nadie podía pensar que el Emperador corriese el riesgo de convocar una nueva.

Finalmente, es importante notar que, al final del Preámbulo, se dice que la Constitución será «del tenor siguiente», o sea, tendrá la redacción que viene después, lo que evidencia que el Preámbulo no era parte de la Constitución, no pudiendo, por eso, ser invocado como norma constitucional vinculante y dotada de eficacia jurídica. Ese procedimiento sería adoptado en todas las Constituciones brasileñas que vinieran después. Nótese, al final, que el Emperador decreta la Constitución "en nombre de la Santísima Trinidad". Aquí también se contiene una ambigüedad, pues tal afirmación no era señal de una intensa religiosidad del Emperador que, en realidad, nunca demostró gran fervor religioso. Se puede interpretar esa invocación a la Santísima Trinidad como artificio político, pues agradaría a la Iglesia Católica, que ejercía fuerte influencia en el panorama político brasileño $y$, al mismo tiempo, aquella referencia recordaría que el Emperador estaría ejerciendo un "derecho divino" al decretar la Constitución, lo que estaría de acuerdo con su formación absolutista y sería una fuerte apelación a la obediencia incondicional por el pueblo, afirmando el "carácter sagrado" de la Constitución.

A pesar de esa retórica, el Emperador encontró gran resistencia entre los líderes políticos brasileños. Debe observarse que la inmensidad del territorio brasileño, cuya ocupación se realizó a partir de puntos aislados, favoreció una gran diversidad económica y social, sin la posibilidad de la presencia efectiva del gobierno central, lo que trajo como resultado la formación de muchos núcleos políticos regionales, con intereses particulares. Tales circunstancias dificultaron mucho la afirmación de la autoridad nacional de Don Pedro, que en 1831 fue obligado a abdicar, dejando en su lugar a su hijo con apenas ocho años de edad, que algunos años después asumió el gobierno del Imperio con el 
título de Don Pedro II. A pesar de esas graves perturbaciones, la Constitución fue mantenida y en gran parte fue efectivamente aplicada, habiendo sufrido algunas enmiendas significativas procurando fortalecer a los líderes políticos regionales y establecer el equilibrio entre los poderes del Emperador y del Parlamento. No obstante las limitaciones, se puede decir que hubo coherencia entre el Preámbulo, la Constitución y las circunstancias políticas.

\section{La Constitución de 1891.}

El día 15 de noviembre de 1889, como consecuencia de un conjunto de circunstancias políticas, económicas y sociales y por decisión de una coalición de fuerzas extremadamente heterogéneas, fue proclamada la República en Brasil. Ese mismo día asumió el poder un Gobierno Provisional que publicó una proclama anunciando la elección de una Asamblea Nacional Constituyente, que debería elaborar una Constitución "republicana y federal", reflejando las ideas de un movimiento político de expresión nacional.

Aunque con serias limitaciones, la Asamblea Constituyente fue elegida por el pueblo. No fue dado derecho de voto a las mujeres ni a los analfabetos, cuyo número era muy elevado entre la población brasileña, utilizándose el sistema de voto abierto, no secreto, lo que facilitó la intimidación de los electores más pobres y coaccionó a los que, desde el punto de vista económico o incluso para acceder a posiciones sociales más elevadas, dependían de líderes políticos. A pesar de estas $y$ otras limitaciones, los constituyentes fueron elegidos y hubo libertad para que las convicciones políticas fuesen manifestadas, debiéndose resaltar que las divergencias de carácter político eran, básicamente, la expresión de conflictos de intereses. De un lado estaban los conservadores, en gran mayoría ligados a la propiedad de la tierra y a privilegios que venían desde tiempos coloniales o habían sido adquiridos durante el período monárquico. De otro lado estaban los que se calificaban como liberales, influenciados por los autores que habían inspirado las revoluciones burguesas de los siglos XVII y XVIII, y por la experiencia política de los Estados Unidos de América.

Desde 1870 se venía desarrollando una campaña en favor de la República, habiéndose alimentado núcleos republicanos en varias Provincias brasileñas sin que nunca se halla llegado a una integración nacional de esos núcleos. Esa imposibilidad de unificación era el reflejo de intereses regionales, diferenciados y muchas veces con- 
flictivos, que quedaron muy claramente expuestos por las divergencias, muy agudas $y$ expresamente manifestadas, en cuanto a la adopción del Federalismo. En varias Provincias fueron publicados manifiestos republicanos, pero mientras que las provincias del Sur $y$ del Centro-Sur propugnaban una organización federal de tipo norteamericano como la solución natural y conveniente para la integración brasileña, las regiones Norte y Nordeste, más atrasadas y con una organización social semifeudal y también más dependientes del gobierno central, repudiaban con gran vehemencia la propuesta federal. Los republicanos de esas regiones consideraban al federalismo un riesgo para la unidad brasileña y una forma de otorgar plena libertad a las Provincias más ricas y desarrolladas, comprometiendo la solidaridad nacional.

En ese ambiente de discrepancias fue elegida y constituida la Asamblea Nacional Constituyente que debatió ampliamente las principales propuestas para la Constitución concluyendo su tarea en 1891. Nació, así, la primera Constitución republicana brasileña que fue promulgada y publicada con el siguiente:

\section{Preámbulo}

Nosotros, los Representantes del Pueblo Brasileño, reunidos en Congreso Constituyente, para organizar un régimen libre y democrático, establecemos, decretamos y promulgamos la siguiente Constitución de la República de los Estados Unidos de Brasil.

El primer punto a resaltar en ese Preámbulo es la afirmación de legitimidad de los constituyentes por haber sido elegidos por el pueblo brasileño. Ahí está implícito el reconocimiento de la soberanía popular, pues fue en nombre del pueblo, $y$ en cuanto que sus representantes, que los constituyentes elaboraron la Constitución. Coherente con los ideales republicanos, el Congreso Constituyente "estableció, decretó y promulgón la Constitución, ejerciendo un derecho cuyo titular era el pueblo, del cual los miembros del Congreso eran representantes. Al mismo tiempo que se da ese reconocimiento de que los constituyentes eran sólo representantes y no elaboraron la Constitución en su propio nombre o en el ejercicio de un derecho individual de cada uno, existe también, en ese Preámbulo, la mención de que la Constitución era expresión de la voluntad del pueblo y que de ahí venía su autoridad. EI principal interesado en obedecer la Constitución era el pueblo, cuya voluntad expresaba. 
Otro punto fundamental de ese breve Preámbulo es la afirmación de que los representantes habían sido elegidos «para organizar un régimen libre y democrático". En esa afirmación se encuentra el rechazo a la monarquía, al absolutismo y a todas las formas de tiranía, mas también la afirmación de opción por un tipo de sociedad en la cual los individuos deberían tener plena libertad individual, a la vez que libertad económica, sin riesgos ni limitaciones para la propiedad privada y para el uso de los bienes. Todo eso era parte del ideario liberal y republicano. Es importante recordar, también, que Brasil había mantenido legalmente la esclavitud hasta el 13 de mayo de 1888, lo que había contribuido a que los propietarios de esclavos, a pesar de ser conservadores, se aliasen con los republicanos, especialmente porque no habían sido indemnizados por la pérdida de los esclavos.

Al mismo tiempo, debe observarse que, aunque apenas divulgadas entre algunos intelectuales y sin mucha aceptación, habían llegado a Brasil las ideas socialistas y anarquistas. Estas ideas no llegaron a ser debatidas en la Constituyente, pero probablemente ejercieron cierta influencia para que algunos de los constituyentes quisieran hacer la afirmación expresa de la libertad como fundamento de la sociedad. Recuérdese, a este propósito, que estaba reciente la publicación de la Encíclica Rerum Novarum, del Papa León XIII, que había despertado en amplios sectores de la Iglesia Católica, muy influyente en Brasil, el temor de que la lógica preocupación por la «cuestión social" pudiese despertar ideas revolucionarias inconvenientes para la libertad económica y religiosa.

Otro punto muy significativo de ese Preámbulo es la referencia a la Constitución de la "República de los Estados Unidos de Brasil», en donde queda patente la gran influencia ejercida por los Estados Unidos de América. Esta influencia fue expresamente mencionada por varios constituyentes en muchas ocasiones. Fue especialmente importante, a este respecto, la actuación del constituyente Ruy Barbosa, abogado de gran prestigio que había participado activamente en la campaña abolicionista y que era profundo conocedor de la historia política y de la Constitución de los Estados Unidos. En su opinión, la riqueza y el poderío de los Estados Unidos, visibles a pesar de su poco desarrollo en el plano internacional, se debia, en gran parte, a su Constitución republicana, con separación de poderes y federal.

En cuanto a la opción republicana había amplio consenso, lo que se confirma por el hecho de que no llegó a existir lucha en Brasil para la implantación de la República, ni hubo tampoco ningún movimiento significativo buscando restaurar la Monarquía. En lo tocante a la 
opción federal, hubo algunos debates pero los federalistas tenían gran mayoría en la Constituyente. Al lado de eso, existe el hecho de que el manifiesto publicado por destacados líderes civiles y militares el 15 de noviembre de 1889, proclamando la República de Brasil, ya decía que la futura Constitución sería "republicana y federal», condicionando, de ese modo, la opción de los constituyentes.

Lo que se decidió, entonces, fue transformar a las antiguas Provincias brasileñas en Estados autónomos y decir que éstos se unían para formar el Estado brasileño. Era una ficción, porque Brasil ya existía como Estado, pero fue una manera de hacer más evidente la utilización del modelo norteamericano. En opinión de muchos constituyentes la fórmula "Estados Unidos de Brasil" era la que más convenía para la organización política de una sociedad libre y democrática. De ese modo, aunque muy sintético, el Preámbulo expresó las ideas políticas básicas predominantes en la Constituyente, debiéndose admitir que aquéllas eran las ideas predominantes entre los brasileños que habian elegido a los constituyentes.

\section{La Constitución de 1934.}

La constitución de 1891 duró hasta 1930, cuando un golpe de Estado puso fin a la Primera República brasileña. Esa Constitución sólo fue aplicada en parte durante los primeros años de vigencia pues, aunque la Constitución estableciese que el Presidente de la República sería elegido por el pueblo, los constituyentes decidieron, al final de los trabajos, que el primer presidente sería elegido por la Constituyente $y$ escogieron al general Deodoro da Fonseca, que había sido signatario de la Proclamación de la República.

Con ocasión de fuertes divergencias políticas, manifestadas en varios puntos del país, el Presidente de la República, inexperto y sin fuerza ante ataques políticos, renunció a su mandato antes de haber llegado a la mitad del período presidencial y quien asumió la presidencia fue el Vicepresidente, Floriano Peixoto, también militar, pero con bastante energía y con vocación para el ejercicio del poder. Fue cuestionada la constitucionalidad de su permanencia en el cargo, toda vez que, en aquella circunstancia, se preveía en la Constitución la realización de nuevas elecciones y el Vicepresidente sólo debía quedar en el cargo hasta la elección, por el pueblo, del nuevo Presidente. Mas Floriano Peixoto permaneció en la jefatura del gobierno, caracterizándose formalmente, en cuanto al Poder Ejecutivo, como una dictadura. 
Eso restringió bastante la aplicación de la Constitución pero no impidió que el Legislativo continuase funcionando e hiciese varias leyes necesarias para la instauración del régimen republicano.

Al final del mandato de Floriano Peixoto se realizaron elecciones y el pueblo eligió a un civil, cerrándose el que fue llamado "periodo militar» de la Primera República. Ésta fue bastante complicada pues, en los primeros años del siglo veinte, tuvo inicio la creación de un parque industrial en Brasil, especialmente en el Estado de São Paulo. Ya al final del siglo diecinueve habían llegado a Brasil muchas familias de inmigrantes europeos, contratados para sustituir a los trabajadores esclavos en la agricultura. Con esas familias llegaron nuevas ideas y nuevas costumbres, siendo especialmente importante señalar que muchos de esos inmigrantes, sobre todo italianos y españoles, pasaron a vivir en las ciudades y a trabajar en la industria. Con ellos llegó la noción de derechos de los trabajadores.

La Primera República brasileña estuvo marcada por muchos conflictos. Hubo varias intervenciones federales en algunos Estados miembros y se llegó a afirmar en el Parlamento nacional que algunos Estados estaban confundiendo autonomía con soberanía. Cada Estado adoptó su propia Constitución y varias de ellas contenían preceptos contrarios a la Constitución federal. La novedad de la organización federal causaba problemas, bien por inexperiencia, bien porque los antiguos líderes provinciales, convertidos después de 1891 en líderes estatales, querían más libertad de acción y no aceptaban restricciones y sacrificios impuestos por el gobierno central para proteger a los Estados menos desarrollados.

La primera experiencia brasileña de federalismo, que duró desde 1891 a 1930, reveló aspectos positivos y negativos. Los Estados de las regiones Sur y Centro-Sur aprovecharon la autonomía para acelerar su desarrollo económico y social. La influencia de los inmigrantes fue significativa en esas regiones, en varios sentidos. Así, por ejemplo, fue inevitable el establecimiento de nuevas condiciones en las relaciones de trabajo y, a pesar de la represión policial, surgieron los sindicatos y se desarrolló la noción de derechos de los trabajadores.

A la vez que eso, en pocas décadas los descendientes de los inmigrantes comenzaron a tener acceso a cargos públicos y consiguieron un ascenso social que les permitió ocupar posiciones que anteriormente estaban reservadas a las elites tradicionales. De ese modo, en los Estados más desarrollados fue inevitable cierta modernización, favoreciendo la movilidad social, en tanto que en otros Estados la auto- 
nomía favoreció el mantenimiento de grupos oligárquicos privilegiados, con absoluto dominio de la vida política. Desde esa perspectiva, se puede decir que el federalismo contribuyó al mantenimiento de las desigualdades regionales y a la ampliación de los desniveles sociales en la parte más retrasada del país.

En los lugares en que era mayor la concentración de trabajadores urbanos, como Rio de Janeiro y São Paulo, surgieron al inicio del siglo veinte varias organizaciones de trabajadores y con ellas las primeras huelgas, violentamente reprimidas por las fuerzas policiales, poniéndose de moda entre los gobiernos la expresión "la cuestión social es cuestión de policía". Así, la libertad y la democracia, previstas en el Preámbulo de la Constitución, sufrieron serias restricciones, especialmente en cuanto a los grupos más modestos de la población y para aquéllos que hablaban y pretendían actuar en favor de la libertad y de la democracia.

La utilización del sistema de voto abierto, con el mantenimiento de la discriminación de las mujeres y los analfabetos, la distribución de empleos públicos como forma de ganar electores, además de otros vicios electorales, llevó a la democracia a un precario estado. Al final de la década de los años veinte los graves problemas sociales y políticos llevaron a la aglutinación de fuerzas políticas heterogéneas, incluyendo aspiraciones a la moralidad pública, a la limpieza electoral y a la justicia social. Y así en 1930 un golpe de Estado cerró esa fase republicana y constitucional.

Instaurado un gobierno provisional, liderado por Getúlio Vargas, tuvo inicio un período de gobierno dictatorial, que luego comenzó a ser contestado por muchas de las fuerzas políticas que habían colaborado en su implantación. La contestación a la dictadura fue más fuerte en el Estado de São Paulo, donde ya había un significativo desarrollo industrial y unos líderes políticos muy activos. Se comenzó a exigir la realización de elecciones y la convocatoria de una Asamblea Nacional Constituyente y hubo, incluso, un movimiento armado que fue denominado "Revolución Constitucionalista", a través del cual el Estado de São Paulo, con un ejército de voluntarios y el apoyo de su Fuerza de Policía Militar estatal, se enfrentó al gobierno federal. Ese movimiento acabó siendo sofocado por las fuerzas federales, pero el resultado deseado fue conseguido en 1933 cuando se convocó una Asamblea Nacional Constituyente y sus miembros fueron elegidos por el pueblo.

La Constituyente de 1934 presentó varias innovaciones de gran importancia, comenzando por el nuevo sistema electoral implantado 
por el gobierno provisional y que ya fue utilizado para la elección de los constituyentes. La mujeres consiguieron el derecho de sufragio activo y pasivo y el voto pasó a ser secreto, lo que otorgó enorme independencia al electorado. Por primera vez, Brasil tuvo una Asamblea Constituyente en la cual estaba presente la mujer, al lado de representantes de los trabajadores, declaradamente en favor del socialismo. Al mismo tiempo, reflejando las propuestas políticas en boga en Europa, había corporativistas, influenciados sobre todo por los acontecimientos de Italia, además de adeptos de un nacionalismo elitista que hacía recordar al nazismo. Pero también estaban presentes los representantes de las elites tradicionales, apoyadas en el latifundio y en la actividad rural, así como representantes del capitalismo industrial y financiero.

Esa Asamblea Nacional Constituyente aprobó en 1934 la nueva Constitución de Brasil, que fue presentada con el siguiente:

\section{Preámbulo}

Nosotros, los representantes del Pueblo Brasileño, poniendo nuestra confianza en Dios, reunidos en Asamblea Nacional Constituyente para organizar un régimen democrático, que asegure a la Nación la unidad, la libertad, la justicia y el bienestar social y económico, decretamos y promulgamos la siguiente Constitución de la República de los Estados Unidos de Brasil.

Este Preámbulo, aunque sintético, es revelador de la heterogeneidad de las fuerzas políticas presentes en la Constituyente y muestra que hubo un esfuerzo para conciliar ideas, creencias, intereses y objetivos bastante diferenciados. El punto en común, en relación al cual todos estaban de acuerdo y que se consideró importante resaltar desde el principio, fue la afirmación de la legitimidad de la Asamblea Nacional Constituyente, que reunía a los representantes del pueblo brasileño. Eso debería asegurar la autoridad de la Constitución y su supremacía, lo que en aquel momento era importante dejar claro, porque la Asamblea Constituyente habia sido, si se puede hablar así, impuesta al gobierno provisional liderado por Getúlio Vargas, que se consideraba intérprete legítimo de los intereses nacionales porque había llegado al gobierno con apoyo de una serie de opiniones muy amplias y diversificadas.

La expresión "confianza en Dios" que se encuentra en el Preámbulo fue incluida, muy probablemente, por influencia de los 
constituyentes católicos tradicionales pero también por aquéllos que se encontraban temerosos del crecimiento del comunismo, del avance "de Rusia", como decían en Brasil los sacerdotes católicos y también los empresarios conservadores, expresando el pensamiento y el temor de los grandes propietarios. Es oportuno recordar que en aquel momento ya existía en Brasil un Partido Comunista, que estaba creciendo y comenzaba a entrar en conflicto con los militantes de Acción Integrista, versión brasileña del nazismo.

Como consta en el Preámbulo, los constituyentes habían recibido del pueblo brasileño el encargo de organizar un régimen democrático, lo que dejaba claro el rechazo de la dictadura. Entre tanto, reflejando y procurando conciliar las diferentes corrientes del pensamiento político $y$ los diferentes intereses representados en la Constituyente, el Preámbulo hace una enumeración de objetivos específicos comprendidos en la idea de régimen democrático. La referencia expresa a la "unidad», como aparece en el Preámbulo, es un reflejo de las luchas políticas que habían desembocado en la lucha armada. Los líderes del Estado de São Paulo habían sido acusados de "separatistas", habiéndose afirmado que la exigencia de convocatoria de una Asamblea Constituyente había sido apenas un pretexto, pues el objetivo era separar el Estado de São Paulo del resto de Brasil. En tales circunstancias, la afirmación de la unidad como objetivo nacional era importante.

La libertad continuaba siendo el primero de los derechos para la burguesía liberal, pero era una necesidad general, sentida por todos. Las referencias a la justicia y al bienestar social y económico son, de un lado, el reflejo de nuevas influencias que habian despertado nuevas aspiraciones $y$, de otro lado, tenían la intención de demostrar que no era necesario hacer una revolución comunista para que hubiese justicia y bienestar social y económico. Se pretendía mostrar al pueblo que todos, incluso las elites tradicionales, estaban de acuerdo en cuanto a esos objetivos, hasta el punto de que estaban expresados en el Preámbulo de la Constitución. Esa referencia abstracta a tales objetivos, hecha en el Preámbulo, no generaba derechos ni obligaciones y podría tener efecto político, calmando a los insatisfechos.

Finalmente, la reiteración de la expresión «Estados Unidos de Brasil", repitiendo lo que se había hecho en 1891, era una reafirmación de la opción por la organización federal y, al mismo tiempo, una confirmación de la unidad de todos los Estados brasileños bajo la misma Constitución. 


\section{La Constitución de 1937.}

Los hechos políticos ocurridos en Brasil después de 1934 mostraron que la Asamblea Nacional Constituyente de aquel año pudo haber sido, efectivamente, mucho más la exigencia de algunos líderes políticos poderosos que del pueblo brasileño. En realidad, el pueblo, en su gran mayoria, tenía más razones para estar satisfecho con el gobierno provisional que para lamentar la caída del anterior gobierno constitucional. Lo que todos sabían era que en el régimen anterior había corrupción administrativa, favorecimiento de amigos y correligionarios, fraude electoral, además de muchos privilegios establecidos por ley en beneficio de las elites sociales y económicas que representaban no más del diez por ciento de la población. Las relaciones de trabajo eran injustas y no había protección para los derechos de los trabajadores. Además de eso, las mujeres no disfrutaban de derechos políticos y se les prohibía el acceso a los cargos públicos de mayor importancia. Todo eso comenzaba a ser cambiado por el gobierno provisional, que encontraba facilidad para introducir las innovaciones porque el Parlamento había sido disuelto y no había oposición activa, a no ser por medio de algunos periódicos leídos por una pequeñísima parte del pueblo.

Un hecho politico de gran importancia, con graves consecuencias en el futuro inmediato, fue la decisión de la Asamblea Constituyente de elegir al primer Presidente de la República que debía ser elegido por el pueblo después de promulgada la Constitución, repitiendo lo que había hecho la Constituyente de 1891. El Presidente elegido por los constituyentes fue justamente el jefe del gobierno provisional, Getúlio Vargas, lo que demuestra que gozaba de prestigio popular y era considerado un buen gobernante. Es evidente que esa decisión de los constituyentes fue producto, también, de la habilidad política de Getúlio Vargas, que sería varias veces comprobada hasta su trágica muerte, por suicidio, en 1955, cuando ocupaba otra vez la presidencia de la República, esta vez elegido por el pueblo.

Tras la promulgación de la Constitución de 1934 el Parlamento y los partidos políticos volvieron a funcionar normalmente. En el ambiente de euforia política provocado por la Constituyente, dos organizaciones politicas radicales pasaron a actuar intensamente: el Partido Comunista y Acción Integrista. Hubo conflictos violentos en las calles y se fue desarrollando un clima de temor e inseguridad. En 1935 el gobierno federal anunció haber descubierto y desmantelado un plan de los comunistas para el asesinato simultáneo de jefes militares, en varios puntos del país, y para la inmediata toma del poder por las 
armas. Hubo muchas presiones y el Presidente de la República obtuvo el consentimiento del Congreso Nacional para asumir poderes excepcionales y suspender garantías constitucionales. En 1937, valiéndose de la situación de inestabilidad y justificándose en el "peligro comunistan, supervalorado, que aterrorizaba a las elites sociales, los grandes propietarios y la Iglesia Católica, Getúlio Vargas consiguió el apoyo de prácticamente todos los gobernadores de los Estados para implantar un sistema dictatorial, que denominó "Estado Nuevo".

Para formalizar la implantación del nuevo sistema, Getúlio Vargas publicó un decreto revocando la Constitución de 1934 y publicando una nueva, preparada en secreto por juristas de su confianza, conteniendo el siguiente:

\section{Preámbulo}

El Presidente de la República de los Estados Unidos del Brasil: Atendiendo a los legítimos deseos del pueblo brasileño a la paz política $y$ social, profundamente perturbada por conocidos factores de desorden, resultantes de la creciente agravación de los decididos partidarios, que una notoria propaganda demagógica procura desnaturalizar en lucha de clases, y de la extremación de conflictos ideológicos, tendentes, por su desarrollo natural, a resolverse en términos violentos, colocando a la Nación bajo la funesta inminencia de la guerra civil;

Atendiendo al estado de aprehensión creado en el país por la infiltración comunista, que se torna cada día más extensa y profunda, exigiendo remedios de carácter radical y permanente;

Atendiendo a que, bajo las instituciones anteriores, no dispone el Estado de medios normales de preservación y de defensa de la paz, de aseguramiento y de bienestar del pueblo;

Con el apoyo de las fuerzas armadas y cediendo a las inspiraciones de la opinión nacional, unas y otras justificadamente aprehensivas ante los peligros que amenazan a nuestra unidad y de la rapidez con que se viene procesando la descomposición de nuestras instituciones civiles y políticas;

Resuelvo asegurar a la Nación su unidad, el respeto a su honra y su independencia, y al pueblo brasileño, bajo un régimen de paz política y social, las condiciones necesarias para su seguridad, su bienestar y su prosperidad, Decretando la siguiente Constitución, que se cumplirá desde hoy en todo el país: Constitución de los Estados Unidos de Brasil. 
Antes de todo, el texto publicado por el decreto de Getúlio Vargas no era, evidentemente, una Constitución, no siendo más que una imposición dictatorial. La última frase del Preámbulo deja claro ese carácter, cuando determina el cumplimiento inmediato de las reglas contenidas en aquel texto, que son representativas de la voluntad del dictador. Además de eso, en los últimos artículos de esa falsa Constitución estaba dispuesto que sería sometida al pueblo para que fuese refrendada, lo que, en realidad, jamás ocurrió, aunque Getúlio Vargas hubiera permanecido en el gobierno hasta 1945, cuando fue destituido por un movimiento político-militar.

Ese Preámbulo, en síntesis, es apenas un manifiesto político por medio del cual el dictador intenta convencer al pueblo, sobre todo a las clases superiores que tenían interés en el mantenimiento de sus privilegios y temían la pérdida de su patrimonio, de que la violencia política había creado el riesgo de una guerra civil. Denunciando la creciente infiltración comunista, llama la atención hacia el "peligro comunista" el mismo argumento que sería utilizado en 1964 para la implantación de otra dictadura- y concluye que se torna indispensable el establecimiento de nuevas instituciones, porque las que existían no otorgaban al Estado los medios necesarios para garantizar la paz y el bienestar del pueblo.

Nótese que el Preámbulo no hace referencia a los partidos políticos, dando como justificación para el decreto dictatorial los «deseos de la opinión nacional», expresión vaga que procura ocultar el hecho de que no hubo consulta a cualquier órgano representativo o entidad que expresase la voluntad y los intereses de la población. Hubo, en efecto, el apoyo de las fuerzas armadas, expresamente mencionado en el Preámbulo, pero eso, evidentemente, no puede ser confundido con la manifestación del acuerdo del pueblo que legitima un golpe de Estado. A pesar de los artificios retóricos, el Preámbulo deja claro que estaba siendo implantada una dictadura y que ésta procuraba disfrazar su verdadera naturaleza escondiéndose detrás de un texto que fue llamado impropiamente Constitución.

\section{La Constitución de 1946.}

La dictadura de Getúlio Vargas fue la confirmación de que "todas las dictaduras se parecen". Recibida sin entusiasmo y, también, sin ninguna manifestación vigorosa de oposición, tuvo un inicio tranquilo, entre otras razones, por el hecho de que el Congreso Nacional había sido cerrado el mismo día de la publicación del decreto implantando la 
dictadura, los partidos políticos dejaron de existir, fueron prohibidas las manifestaciones públicas de carácter político y el Poder Judicial estaba impedido para asegurar los derechos fundamentales.

Durante ese período dictatorial fue modernizada la Administración Pública, se introdujo el planeamiento en el sector público, se procuró racionalizar el sistema tributario y el Estado comenzó a tener una presencia más fuerte en la sociedad brasileña, incluso dando apoyo a actividades económicas básicas. A la vez, se desarrolló una organización sindical protegida por el Estado. Entre tanto, como siempre ocurre en las dictaduras, todas las formas de oposición fueron prohibidas, creándose un aparato de vigilancia y seguridad que actuaba arbitrariamente, sin reglas ni limitaciones legales. Fue creada una Policía Especial para disolver manifestaciones públicas de carácter opositor, practicándose violencia, prisiones ilegales y tortura, instalándose un tribunal especial para casos de seguridad nacional. Los gobiernos de los Estados fueron entregados a Interventores que eran meros agentes del gobierno central, sin autonomía. En la Administración Pública se instaló una casta privilegiada, liderada por amigos y fieles seguidores del dictador. El sistema sindical acabó en un sindicalismo controlado por el Ministerio de Trabajo.

Adoptando una actitud populista, Getúlio Vargas procuraba aparecer delante de la opinión pública como "padre de los pobres", preocupado por el bienestar de los trabajadores y la asistencia a las clases más pobres de la población. Se desarrolló el culto a la personalidad y en todas las instituciones públicas era obligatoria la colocación de una fotografía del dictador en un lugar destacado. En las escuelas los alumnos eran educados para elogiar "al Presidente Getúlio Vargas" como el gran benefactor de la Patria. Coronando todo eso, fue establecido un rígido sistema de censura en la prensa, dirigido por el Departamento de Prensa y Propaganda.

Tras la eclosión de la segunda guerra mundial, Getúlio Vargas tomó una actitud ambigua, dejando entrever que tenía más simpatía por el nazi-fascismo. Entre tanto, el hundimiento de algunos navíos mercantes brasileños, atribuido a submarinos alemanes que querían impedir que Brasil proveyese a los Aliados anti-nazistas y anti-fascistas de bienes esenciales y materia prima de carácter estratégico, tornó inevitable la entrada de Brasil en la guerra al lado de los Aliados. En ese ambiente, favorecido por las circunstancias, Getúlio Vargas construyó una gran industria siderúrgica que fue de gran importancia para el desarrollo del parque industrial brasileño e inició la exploración del petróleo, lo que también favoreció mucho la economía. 
Terminada la guerra, los militares brasileños que habían convivido con los militares de los países que defendían la democracia se unieron a la oposición democrática, que, aunque impedida de organizarse y de manifestarse públicamente, ya era muy fuerte en Brasil. Así, en 1945, Getúlio Vargas fue retirado del gobierno, sin que hubiese lucha, iniciándose la democratización del país. Un gobierno provisional convocó una Asamblea Nacional Constituyente, los partidos políticos fueron rápidamente organizados, sin ninguna restricción ideológica, en un espectro que incluía partidos ultraconservadores, otros moderados y también adeptos de la izquierda más extrema, como el Partido Comunista. Se adoptó un sistema electoral democrático, con voto secreto y amplia extensión de los derechos políticos, quedando excluidos los analfabetos.

Instalada la Asamblea Constituyente, sus trabajos fueron desarrollados en un ambiente de entusiasmo por el restablecimiento de la libertad y por la posibilidad de implantación de un ordenamiento jurídico democrático. De ese modo, en 1946, después de algunos meses de intensa actividad, fue aprobada la nueva Constitución, con el siguiente:

\section{Preámbulo}

Nosotros, los representantes del pueblo brasileño, reunidos bajo la protección de Dios, en Asamblea Constituyente para organizar un régimen democrático, decretamos y promulgamos la siguiente Constitución de los Estados Unidos de Brasil.

Como puede comprobarse, los Constituyentes de 1946 optaron por un Preámbulo breve, reproduciendo, casi íntegramente, el Preámbulo de la Constitución de 1934. Fue recordada la condición de representantes del pueblo, que daba legitimidad a los Constituyentes $y$ a la Constitución por ellos aprobada. Una vez más fue invocada la protección de Dios, siendo oportuno destacar que ya se iniciaba, en el plano mundial, la disputa entre el sistema capitalista y el comunismo soviético, existiendo aún en Brasil el pavor al comunismo, representado como el anticristo, el enemigo de la libertad y la propiedad privada. Se reafirmó que la Asamblea Constituyente había sido convocada para organizar un régimen democrático, pero el predominio de conservadores y liberales burgueses, contrarios a la intervención del Estado y a la extensión de los derechos sociales, hizo que no se hiciese una enumeración de objetivos específicos. Se afirmó que la libertad estaba implícita en la afirmación del carácter democrático del régimen, conside- 
rándose, por otra parte, que la referencia a la ujusticia y al bienestar social y económico" sería una concesión a las propuestas socialistas y, en última instancia, podría servir de apoyo a un avance comunista. Por eso no fue reproducida esa expresión.

Finalmente, fue adoptada la fórmula "Estados Unidos de Brasil" para reafirmar la opción por la organización federal. No hubo mención a la República en ese Preámbulo porque se consideró que, siendo democrático el régimen, estaría implícita la preservación del sistema republicano, además de que, en aquella Constituyente, no hubo reivindicaciones monárquicas.

\section{La Constitución de 1967.}

Aunque en el Preámbulo de la Constitución de 1946 no se mencionase la justicia ni el bienestar social y económico, durante su vigencia hubo considerables avances en la democratización de la sociedad brasileña, así como una mayor eficacia de la Constitución. En este sentido, fue restablecida la autonomía de los Estados miembros y de los Municipios, los derechos laborales tuvieron aplicación efectiva y en varios aspectos importantes fueron ampliados, en gran parte, gracias al nacimiento de un sindicalismo auténtico, libre del control de gobierno. El hecho político más ambiguo fue la extinción del Partido Comunista por un acto del gobierno, fuertemente influenciado por la Iglesia Católica. El argumento que se usó para justificar este acto fue que la existencia de un Partido Comunista era incompatible con un régimen democrático identificado con el capitalismo. Ese argumento fue recogido por el Tribunal Supremo Federal, debiéndose también señalar que gran parte de la población tenía pavor al comunismo y estaba de acuerdo con las acciones del gobierno cohibiendo cualquier manifestación comunista.

A partir del final de la segunda guerra mundial, en gran parte bajo la influencia de la propaganda y de las tentativas de expansión de la Unión Soviética, la cuestión de los derechos sociales y económicos cobró gran énfasis en los debates sobre democracia y justicia social. La aprobación de la Declaración Universal de los Derechos Humanos por la Organización de las Naciones Unidas, en 1948, fue el punto de partida de una intensificación de las acciones en favor de esos derechos, especialmente de algunos derechos fundamentales, como la libertad y la igualdad. Esos movimientos tuvieron repercusión en Brasil, donde surgieron varias organizaciones católicas con el objetivo de luchar por 
la superación de las injusticias, habiendo sido creadas con ese propósito, entre otras, una organización denominada Juventud Universitaria Católica-JUC y otra Ilamada Juventud Obrera Católica-JOC. En el mapa del sindicalismo obrero surgieron líderes socialistas y comunistas que también siguieron esa línea.

A partir de 1959, con el éxito de la Revolución Cubana, ese debate fue intensificado en Brasil, donde muchos estaban convencidos de que la interferencia del capitalismo internacional, especialmente de los Estados Unidos, era un obstáculo a la justicia social. Aplaudidos con entusiasmo, Fidel Castro y el "Che" Guevara estuvieron en Brasil y fueron condecorados por el gobierno federal brasileño, lo que fue recibido con entusiasmo por muchos militantes políticos, incluso por personas ostensiblemente contrarias al comunismo. Hubo, entretanto, reacciones indignadas de parlamentarios de los partidos de derecha o conservadores, así como de militares convencidos de que el comunismo amenazaba la libertad y la soberanía nacional, y de empresarios que veían amenazadas la libertad económica y la propiedad privada y, sobre todo, de los obispos más influyentes de la jerarquía católica, lo que repercutió fuertemente entre los católicos de todo el país.

En septiembre de 1961 el Presidente de la República, Jânio Quadros, que había sido elegido al final de 1960 con gran mayoría de votos, encontraba una fuerte oposición en el Congreso Nacional. Renunció al mandato sin haber sufrido ninguna coacción para eso, todo llevaba a creer que su intención era provocar la salida del pueblo a las calles pidiendo su vuelta y dándole las condiciones para asumir plenos poderes. El pueblo quedó indignado con la renuncia y no se echó a la calle. En consecuencia, asumió la presidencia de la República el Vicepresidente, João Goulart, ahijado de Getúlio Vargas, ligado al laborismo pero sin gran preparación y sin autoridad política, acusado de estar muy ligado a los líderes sindicales comunistas. En un primer momento, los militares se opusieron a la toma de posesión de la presidencia por Goulart, pero acabaron acordando que el sistema presidencialista de gobierno fuese sustituido por el parlamentarismo, lo que fue hecho mediante enmienda constitucional, habiendo un acuerdo al menos aparente.

El día 1 de abril de 1964 un golpe militar destituyó a João Goulart y la presidencia de la República fue entregada a un militar, el general Castello Branco. En ese mismo momento los jefes militares publicaron un documento titulado Acto Institucional, declarando que continuaba en vigor la Constitución de 1946 pero que en caso de conflicto de normas debería siempre prevalecer el Acto Institucional. Derechos y 
garantías fundamentales fueron suspendidos y se instaló una dictadu$\mathrm{ra}$, parecida a todas las otras, con violencia, prisiones arbitrarias, tortura, corrupción y favoritismo. En realidad la Constitución dejó de existir como verdadera Constitución con la publicación del Acto Institucional, pues ya no tenía eficacia de norma superior. Vinieron después otras órdenes militares, denominados Actos Institucionales o Actos Complementarios, determinaciones arbitrarias sin ninguna legitimidad impuestas como leyes superiores.

Con la intención de crear una apariencia de legitimidad y de normalidad constitucional, el general que ocupaba la presidencia de la República envió al Congreso Nacional un proyecto de Constitución. Es importante destacar que el Congreso Nacional había sido cerrado por los militares y fue después reabierto, pero muchos de sus miembros, elegidos por el pueblo, fueron arbitrariamente cesados de sus mandatos y el Congreso, órgano del Poder Legislativo, tenía prohibido "contestar al régimen" y discutir los Actos Institucionales y Complementarios, debiendo subordinarse a ellos.

Como se puede imaginar, el Congreso aprobó formalmente, sin oposición, el texto enviado por el general-presidente y así fue aprobada y publicada la Constitución de 1967, con el siguiente:

\section{Preámbulo}

El Congreso Nacional, invocando la protección de Dios, decreta y promulga la siguiente Constitución de Brasil.

Los propios términos del Preámbulo dejan expresa la falta de legitimidad de la Constitución aprobada en 1967. Si estaba en vigor la Constitución de 1946, como fue dicho por el Acto Institucional, no tenía base jurídica un acto del Congreso Nacional que sólo era competente para hacer leyes ordinarias y complementarias y para aprobar enmiendas constitucionales, pero siempre subordinado a las normas de la Constitución. El Congreso Nacional no había sido elegido con los poderes de Asamblea Constituyente y así, tanto el Preámbulo, como la pretendida Constitución a que se refiere, no tienen consistencia ni validez jurídica.

Así pues, ese es un falso Preámbulo de una falsa Constitución. La referencia expresa al Congreso Nacional es una confesión de ilegitimidad, la invocación a la protección de Dios fue una simple fórmula retórica para mostrar el rechazo al marxismo, siendo cierto que en aquel 
momento ni el pueblo ni la Iglesia Católica tenían condiciones para influir en una decisión política del mando militar, verdadero autor del nuevo texto presentado como Constitución. $Y$ la referencia sintética a la "Constitución de Brasil», sin mencionar a los Estados o a la federación, dejó claro que no se pretendían respetar los preceptos del federalismo, pues todos los gobernantes, órganos y administradores públicos estaban subordinados a las determinaciones arbitrarias del mando militar superior.

\section{La Constitución de 1969.}

Como es normal en las dictaduras, en 1969 la prensa estaba rigurosamente censurada, cualquier manifestación pública de carácter político que pudiese ser interpretada como crítica al gobierno sería considerada como delito y las decisiones del mando militar superior eran tomadas en secreto. Por todos esos motivos, aunque mucha gente tuviera la convicción de que existían divergencias entre los militares que dominaban políticamente a Brasil, el pueblo recibió con sorpresa del mando militar la noticia de que Brasil pasaba a tener una nueva Constitución.

En realidad lo que se comunicó fue que el texto de la Constitución de 1967 estaba siendo sustituido por otro que recibió la denominación de "Enmienda Constitucional número 1 " y que, en realidad, alteraba gran parte del texto de 1967, restringiendo aún más los derechos y alterando otros puntos sustanciales. El nuevo texto, que en la práctica es generalmente conocido como Constitución de 1969, fue publicado con el siguiente:

\section{Preámbulo}

Los Ministros de la Marina de Guerra, del Ejército y de la Aviación Militar, usando las atribuciones que les confiere el artículo $3^{\circ}$ del Acto Institucional número 16, de 14 de octubre de 1969, en relación con el párrafo $1^{\circ}$ del artículo $2^{\circ}$ del Acto Institucional número 5, de 13 de diciembre de 1968, $y$,

Considerando que, en los términos del Acto Complementario número 38, de 13 de diciembre de 1968, fue decretado, a partir de esa fecha, la suspensión del Congreso Nacional;

Considerando que, decretada la suspensión parlamentaria, el Poder Ejecutivo Federal queda autorizado a legislar sobre todas las 
materias, conforme a lo dispuesto en el párrafo $1^{\circ}$ del artículo $2^{\circ}$ del Acto Institucional número 5, de 13 de diciembre de 1968;

Considerando que la elaboración de enmiendas a la Constitución, comprendida en el proceso legislativo (artículo 49, I), está en la atribución del Poder Ejecutivo Federal;

Considerando que la Constitución de 24 de enero de 1967, en su mayor parte, debe ser mantenida, por lo que, salvo enmiendas de redacción, continúan inalterados las siguientes disposiciones:

Considerando las enmiendas modificativas y de supresión que, de esta manera, son ahora adoptadas y las demás disposiciones de la Constitución, así como las enmiendas adicionales que son introducidas;

Considerando que, hechas las modificaciones mencionadas, todas con carácter de Enmienda, la Constitución podrá ser editada de acuerdo con el texto que a continuación se publica,

Promulgan la siguiente Enmienda a la Constitución de 24 de enero de 1967:

El Congreso Nacional, invocando la protección de Dios, decreta y promulga la siguiente Constitución de la República Federal de Brasil.

Los términos del Preámbulo no dejan duda de que se trata de un acto dictatorial, desprovisto de valor jurídico, conteniendo algunos absurdos que vale la pena destacar. En primer lugar, los tres Ministros militares que firman el texto invocan, como fundamento para su acto, los Actos Institucionales, esto es, órdenes militares arbitrarias anteriores y no la Constitución, lo que, obviamente, significa una autolegitimación, o sea, ninguna legitimación.

La segunda "perla» es la afirmación de que, habiendo determinado por Acto Institucional el cierre del Congreso Nacional en 1968, el Poder Ejecutivo Federal quedara autorizado a legislar sobre todas las materias. Esa atribución de competencia legislativa plena al Poder Ejecutivo, como consecuencia del acto de fuerza que determinó el cierre del Congreso, ya sería un absurdo, pero el absurdo es todavía mayor cuando se pretende confundir a tres Ministros militares con el Poder Ejecutivo. Enseguida se dice que la elaboración de enmiendas a la Constitución, comprendida en el proceso legislativo, se encuentra en la atribución del Poder Ejecutivo Federal. Lo que la Constitución esta- 
blecia era que el Presidente de la República, no el Poder Ejecutivo o los Ministros militares, podía presentar propuestas de enmienda constitucional al Congreso Nacional. Como es evidente, presentar una propuesta de enmienda es bien diferente de la elaboración de enmiendas e imposición de ellas sin discusión ni votación en el Congreso.

Al final, reconociendo que eran tantas las enmiendas que el resultado era un texto nuevo, el Preámbulo añade, ambiguamente, que "la Constitución podrá ser editada de acuerdo con el texto que a continuación se publica». Cualquier persona que tenga algún conocimiento de Derecho Constitucional sabe que, aprobada una enmienda constitucional, se incorpora al texto existente, no siendo necesaria nueva publicación formal del texto constitucional íntegro. En resumen, ese Preámbulo es importante por ser un reconocimiento expreso de que el texto de la Constitución de 1969 era una farsa, procurando ocultar, sin éxito, la realidad de la dictadura.

\section{LA CONSTITUCIÓN BRASILEÑA DE 1988.}

La violencia y las arbitrariedades, la corrupción, el favoritismo y otras prácticas antidemocráticas que caracterizaron al régimen militar implantado en 1964 llevaron a su agotamiento. Al final de la década de los setenta ya no se daban las condiciones políticas para el mantenimiento de aquel régimen, pues gran parte de la población que lo había apoyado al principio reconocía que la alegación de proteger la libertad, los derechos fundamentales y los valores cristianos habia sido engañosa. Las imposiciones dictatoriales, la negación de los derechos, las prisiones ilegales, las invasiones arbitrarias de los domicilios de los opositores al régimen, la práctica de la tortura, así como la creación de una clase privilegiada envuelta en la corrupción, nada de eso confirmaba el propósito de salvar a Brasil del peligro del comunismo y resguardar la libertad y los derechos y valores fundamentales del pueblo brasileño. Por todo eso fue creciendo internamente un movimiento, uniendo en el mismo propósito a muchas organizaciones de orígenes diferentes y envolviendo a casi todo el pueblo, exigiendo la democratización del país. La negativa repercusión internacional de todo lo que venía sucediendo en Brasil también influyó para que quedase insostenible el régimen militar.

Así, al final de la década de los setenta, tuvo inicio el retorno a la normalidad constitucional. El Congreso Nacional, acrecido con algunas personas que ocupaban altos cargos públicos, compuso un colegio 
electoral que eligió a un civil para la Presidencia de la República y éste, después de superadas algunas dificultades imprevistas, envió un proyecto de enmienda constitucional al Congreso proponiendo que el Congreso Nacional, una vez elegido, tuviese poder para elaborar una nueva Constitución. No era la fórmula ideal, pues lo que muchos querían era una Asamblea Nacional Constituyente, que fuese elegida por el pueblo con la finalidad exclusiva de elaborar una Constitución. Pero las condiciones políticas eran, todavía, difíciles y el pueblo y los líderes políticos querían que Brasil volviese a la normalidad democrática lo mas rápido posible. Por eso fue aceptada y aplicada la fórmula conciliatoria propuesta $y$ el pueblo eligió diputados $y$ senadores que integrarian el Congreso Nacional que, antes de comenzar a actuar como Poder Legislativo, tendría la función de Asamblea Nacional Constituyente.

Hubo amplia libertad para la organización de partidos políticos, el proceso electoral se desarrolló libremente y con gran participación popular, procediéndose a la elección y siendo inmediatamente iniciado el trabajo de elaboración de la nueva Constitución. Un dato muy importante y altamente decisivo fue la intensa participación del pueblo en los trabajos de la Constituyente que, entre otras cosas, admitió que un cierto número de electores presentase enmiendas al proyecto de Constitución, habiendo muchas propuestas de origen popular, influyendo en las decisiones de los representantes. Aparte de eso, muchas organizaciones representativas de los más diversos intereses $y$ de todas las clases de la población mantuvieron contacto permanente con los constituyentes, ofreciendo sugerencias, haciendo críticas, defendiendo ciertas propuestas y manifestando oposición a otras. Al final, en 1988, fue aprobada la nueva Constitución de Brasil, actualmente en vigor, con el siguiente:

\section{Preámbulo}

Nosotros, representantes del pueblo brasileño, reunidos en Asamblea Nacional Constituyente para instituir un Estado Democrático, destinado a asegurar el ejercicio de los derechos sociales e individuales, la libertad, la seguridad, el bienestar, el desarrollo, la igualdad y la justicia como valores supremos de una sociedad fraterna, pluralista y sin prejuicios, fundada en la armonía social y comprometida, en el orden interno e internacional, con la solución pacífica de las controversias, promulgamos, bajo la protección de Dios, la siguiente Constitución de la República Federal de Brasil. 
El Preámbulo comienza resaltando el hecho de que la Constitución fue elaborada por representantes del pueblo, reunidos en Asamblea Nacional Constituyente, lo que era muy importante, en aquella circunstancia, para dejar bien claro que era el pueblo quien estaba decidiendo a través de sus representantes y por el método reconocido como esencialmente democrático, que es la Asamblea Nacional Constituyente.

Lo que viene después es una afirmación muy clara de compromiso con las exigencias de los Derechos Humanos, contemplados en la Declaración Universal de 1948, en los Pactos de Derechos Humanos aprobados por la ONU en 1966 y en muchos otros documentos básicos que componen el acervo normativo de los Derechos Humanos que hoy vienen determinando, en el mundo, los rumbos para la creación de una nueva sociedad, libre, justa y regida por el derecho. Así es que, después de resaltar que el objetivo de la Asamblea Nacional Constituyente era instituir un Estado Democrático, el Preámbulo hace dos enumeraciones, una referente a los derechos $y$ valores fundamentales y otra relativa al tipo de sociedad que los constituyentes, expresando la voluntad del pueblo, tuvieron en mira.

En la primera enumeración se indica como objetivo "asegurar el ejercicio de los derechos sociales e individuales, la libertad, la seguridad, el bienestar, el desarrollo, la igualdad y la justicia». Es muy importante notar que el Preámbulo habla de asegurar el ejercicio de los derechos, lo que tiene una significación más concreta que una simple declaración de derechos, sin preocupación por su ejercicio. La segunda enumeración se refiere al tipo de sociedad que se pretende conseguir $y$ mantener con base en la Constitución, o sea, "una sociedad fraterna, pluralista y sin prejuicios, fundada en la armonía socialn. A esos derechos, valores y objetivos característicos de una sociedad democrática se añade el compromiso, en el orden interno e internacional, con la solución pacífica de las controversias, rechazando los métodos violentos a los que muchas veces recurren los Estados o grupos organizados, cuando usan la guerra, la represión violenta o la práctica del terrorismo como instrumentos de superación de conflictos, de control social o de preservación de intereses, lo que, en realidad, lleva siempre al aumento de la violencia y no a la preservación de los derechos y a la conquista de la paz.

Después de eso, el Preámbulo invoca la protección de Dios, lo que, en este caso, tuvo el propósito de dejar claro que la mayoría de los constituyentes estaban convencidos de que el pueblo brasileño rechazaba ambas especies de materialismo de las que habla el Papa 
Juan Pablo II en la Encíclica "Laborem Exercens", esto es, el materialismo teórico del marxismo y el materialismo práctico inherente al capitalismo. Por último, el Preámbulo incluye la expresión «República Federal de Brasil», dejando claras las opciones por el sistema republicano y por la organización federal del Estado.

En conclusión, el Preámbulo de la actual Constitución brasileña está bien adecuado a una Constitución democrática según las modernas concepciones. Resalta que la Constitución fue elaborada mediante un sistema democrático y añade que la Constitución es un instrumento para la consecución de objetivos fundamentales de la persona humana y de toda la humanidad. Un dato final que tiene gran importancia es que, en la obra de varios constitucionalistas brasileños contemporáneos, así como en la jurisprudencia, ya es mencionado el Preámbulo como norma constitucional, de eficacia jurídica plena y condicionante de la interpretación y de la aplicación de las normas constitucionales $y$ de todas las normas que integran el sistema jurídico brasileño.

Una constatación preocupante es que los principales órganos del Estado brasileño responsables de la guarda y aplicación de los preceptos Constitucionales, incluyendo al Congreso Nacional, la presidencia de la República y al Tribunal Supremo Federal, no han mantenido estricto respeto a la Constitución en varias ocasiones, por acción u omisión, tomando posiciones contrarias a lo que ella determina. Pero la constatación, indiscutible, de que esa es una Constitución verdaderamente democrática, la más democrática que Brasil ha tenido, alienta la esperanza de que resista las agresiones y tenga plena aplicación, actuando eficazmente como instrumento de garantía de la libertad, de protección de la dignidad humana, de promoción de la justicia, y de consecución de la paz. 